An official publication of the International Society for Energy, Environment and Sustainability (ISEES)
Journal of Energy and
Environmental Sustainability
Journal homepage : www.jees.in

\title{
Numerical Investigation of Convective Heat Loss from Upward Facing Cavity Receivers of Different Shapes at Different Inclinations and Temperatures
}

\author{
Shivam Kumar ${ }^{\mathrm{a}}$, Dadasaheb Jagannath Shendage ${ }^{\mathrm{b}}$, Prafulla Doke ${ }^{\mathrm{b}}$, Shireesh Balwant Kedare ${ }^{\mathrm{a}}$, \\ Shridhar Laxman Bapat $\mathrm{b}^{\mathrm{t}^{*}}$
}

${ }^{a}$ Department of Energy Science and Engineering, Indian Institute of Technology-Bombay, Mumbai, Maharashtra 400076, India

${ }^{b}$ Department of Mechanical Engineering, Indian Institute of Technology-Bombay, Mumbai, Maharashtra 400076, India

\section{A R T I C L E I N F O}

Received : 11 September 2019

Revised : 05 October 2019

Accepted : 18 October 2019

Keywords:

Upward facing cavity, Solar receiver,

Natural convection heat loss,

Receiver design

\begin{abstract}
A B S T R A C T
Scheffler solar concentrator system is commonly used system in India. It is used for industrial process heat, cooking and power generation. It utilizes an upward facing cavity receiver fixed at local latitude. In the present work, upward facing cavity receivers are analysed numerically to study the heat loss by natural convection for six different shapes (cylindrical, cubical, spherical, hemispherical, dome-cylindrical and cone-cylindrical) having equal aperture dimension and cavity depth. CFD analysis is carried out on these different cavity receiversfor isothermal wall temperatures $(600 \mathrm{~K}, 725 \mathrm{~K}, 850 \mathrm{~K}$ and $950 \mathrm{~K})$ at varied inclinations $\left(\theta=0^{0}\right.$ to $-90^{\circ}$ with $10^{\circ}$ interval). The heat loss is observed to increase linearly with increase in surface temperature. Moreover, for a fixed wall temperature, the convective heat loss increases with angle up to a certain inclination angle and then decreases. It is observed that a) cone-cylindrical shaped cavity receiver is the most efficientin terms of solar flux utilization, $b$ ) and the hemispherical cavity has the highest convective heat loss (up to 3.23 times that of cone-cylindrical shape).
\end{abstract}

\section{Introduction}

Cavity receivers are used to capture concentrated solar radiation reflected from a paraboloid dish [Gunther and Shahbazfar, 2011] or Scheffler dish [Munir et al., 2010]. Power generation [Lovegrove et al., 2006] and industrial process heat [Kedare et al., 2006] are some of the commonly used applications of heat obtained through solar dishes with cavity receivers. The overall performance of dish-receiver system depends on factors such as reflectivity of concentrating mirror, thermal losses from cavity, tracking error of dish, etc. While some inefficiencies can't be improved due to practical constraints, heat loss from cavity receiver could be worked on. Convective heat loss constitutes for majority of thermal loss from cavity surface and depends on the geometrical shape of the cavity, aspect ratio, angle of inclination, boundary condition at the wall and the opening ratio. Cavity receivers can have two orientations while in operation: downward facing, where aperture is facing downwards and upward facing, where aperture is facing upwards. In case of downward facing receivers, fluid circulating inside the cavity gets heated up from the hot cavity walls, rises due to buoyancy force and stagnates in the cavity forming stagnation zone. Consequently, the surface exposed for heat interaction reduces, thereby reducing the convective heat loss [Jilte et al., 2014]. In case of upward facing receiver, fluid after absorbing heat from cavity wall, rises and leaves through the aperture opening, thereby allowing for cold air to replace it.
Several investigations are reported in the literature on convective heat loss estimation from downward facing cavity receiver for various shapes [Jilte et al., 2014]. Fewer studies have dealt with upward facing cavities. Liebfried and Ortjohann carried out experimental investigation of convective heat loss from spherical and hemispherical upward facing cavities [Liebfried and Ortjohann, 1995]. They have reported that at temperature of $873 \mathrm{~K}$, convective heat loss can contribute more than $65 \%$ of total heat loss in case of spherical cavity. Investigation on effect of geometry and inclination on upward facing cavity is still not thoroughly investigated and the work presented in this paper is an effort in this direction. Six shape of cavities (cylindrical, cubical, spherical, hemispherical, dome-cylindrical and cone-cylindrical) with isothermal surface conditions are investigated from $600 \mathrm{~K}$ to $950 \mathrm{~K}$ keeping in mind various heat transfer fluids that could be used within this temperature range. For instance, thermic oil has operating range up to $700 \mathrm{~K}$ [Dow, 1997], while molten salt (eutectic mixture of sodium nitrite and potassium nitrate) can operate upto $873 \mathrm{~K}$ under pressurized condition [Iwadate, 1982]. For higher temperature operation (up to $1000 \mathrm{~K}$ ), molten metal (Zinc, Sodium, etc) could be used as a working fluid.

Upward facing cavity receivers are used for Scheffler dish, which have become increasingly relevant in India due to their application for cooking [Brahma Kumaris, 1997], process heat [Taylormade, 2012], airconditioning [GSEP, 2008] and power generation [WRST, 2017].

*Corresponding Author: : slbapat@iitb.ac.in 
Scheffler solar concentrator uses a fixed receiver, inclined at an angle of latitude of the location. In the present analysis, heat loss from cavity receivers with equal aperture dimensions and cavity depths are investigated at varied inclinations $\left(\theta=0^{0}\right.$ to $-90^{0}$ with $10^{0}$ interval).

\section{Numerical Analysis}

Fluent (version 16.2) was employed to simulate and analyze the natural convection through the cavity receivers.

\subsection{Problem formulation:}

Six cavity shapes (cylindrical, cubical, spherical, hemispherical, domecylindrical and cone-cylindrical) are numerically analyzed for convection heat loss. Equal aperture dimension and cavity depth is maintained across all the cavities and compared for their solar flux utilization efficiency in terms of convection heat losses. Moreover, equal aperture dimensions ensure that all the cavities are subjected to similar solar optics. The dimensions of cavity receivers under analysis are shown in Table 1.

Table 1: Dimension of cavity receivers

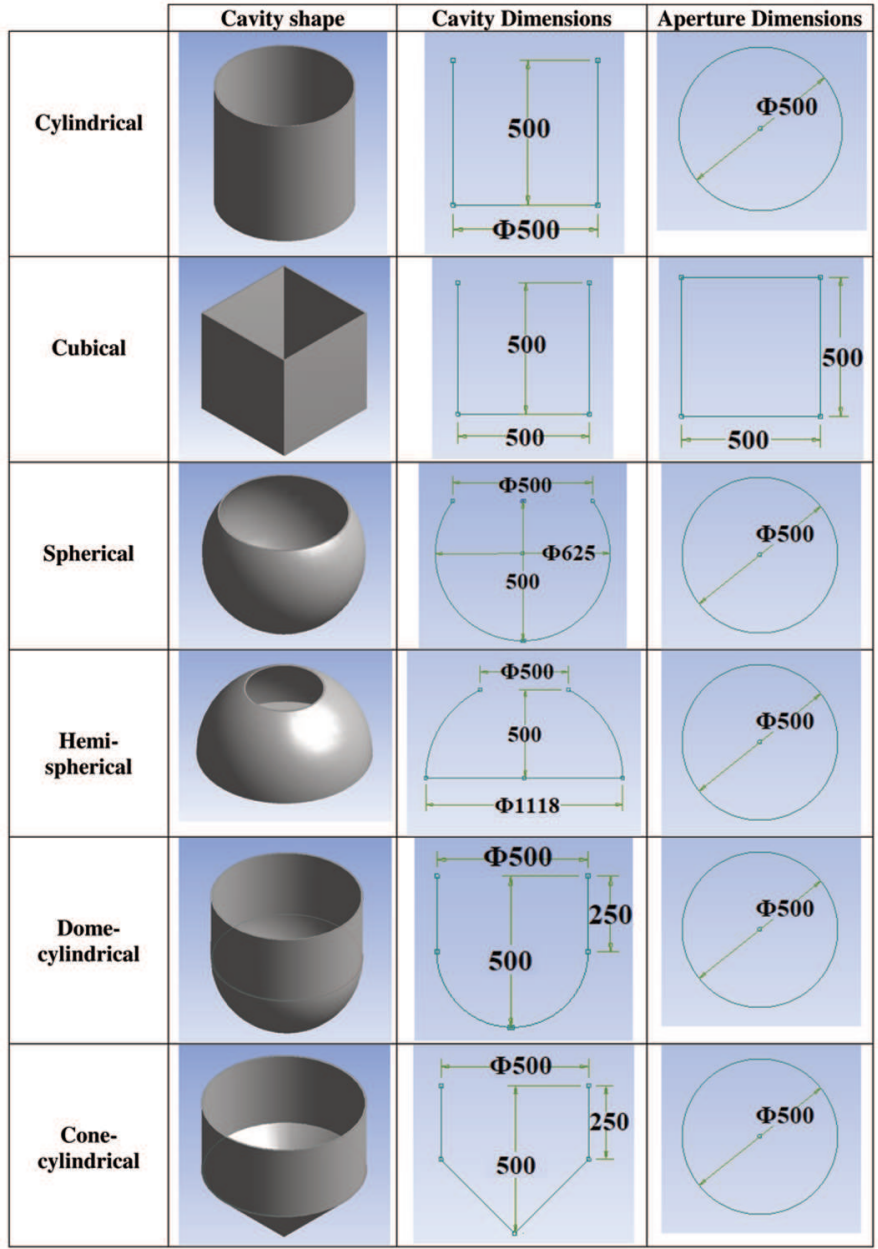

Dome-cylindrical shape consists of a hemisphere at the bottom and a cylindrical shaped upper half, with both shapes occupying $250 \mathrm{~mm}$ depths each. For ease of comparison the cone-cylindrical cavity, like domecylindrical shape, is assigned $50 \%$ portion from the top as cylindrical and the bottom half is conical shaped. The cavities are analysed at varied inclinations $\left(\theta=0^{\circ}\right.$ to $-90^{\circ}$ with $10^{\circ}$ interval). The sign convention for cavity inclination is shown in Table 2.

The cavity receiver, in real life scenarios, are provided with an infinite surrounding at atmospheric condition. In the CFD analysis, this is approximated by placing the receiver in a sufficiently large enclosure (as shown in Figure 1), which ensures that the air flow within the cavity is unaffected by the conditions outside the cavity. In the present analysis, the cavity receivers are placed inside a cylindrical enclosure with 1000 times volume that of the cavity. The enclosure is filled with air at ambient condition (300 $\mathrm{K}$ and $1 \mathrm{~atm})$ uniform throughout.
Table 2: Sign convention for inclination of cavity receiver

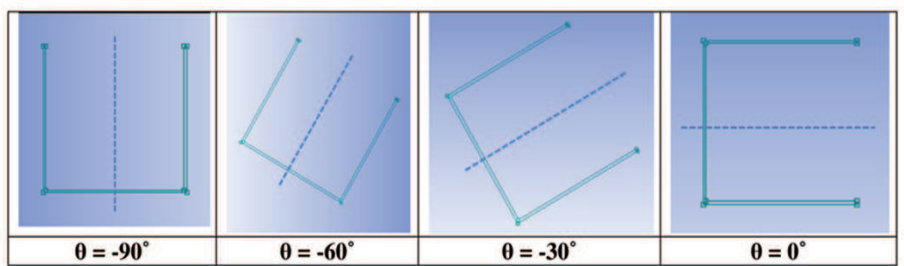

Grid dependency was conducted and is tabulated in Table 3 for a cylindrical cavity inclined at $30^{\circ}$ and inner wall surface at isothermal condition of $950 \mathrm{~K}$. Grid sizing element is varied from $0.5 \mathrm{~m}$ to $0.005 \mathrm{~m}$. The percentage heat loss change reported between grid size $0.1 \mathrm{~m}$ and $0.05 \mathrm{~m}$ is observed to be $6.5 \%$. A difference of $1.14 \%$ is observed between grid sizing element $0.05 \mathrm{~m}$ and $0.01 \mathrm{~m}$ in terms of heat loss. Therefore, grid size element of $0.05 \mathrm{~m}$ is employed for the analysis which yields a grid with $2 \times 10^{5}$ elements. The meshing is done in such a way that cells are fine in the region inside and nearby the cavity, and the mesh progressively coarsens from the cavity towards the enclosure walls. The grid pattern thus obtained is shown in Figure 2.

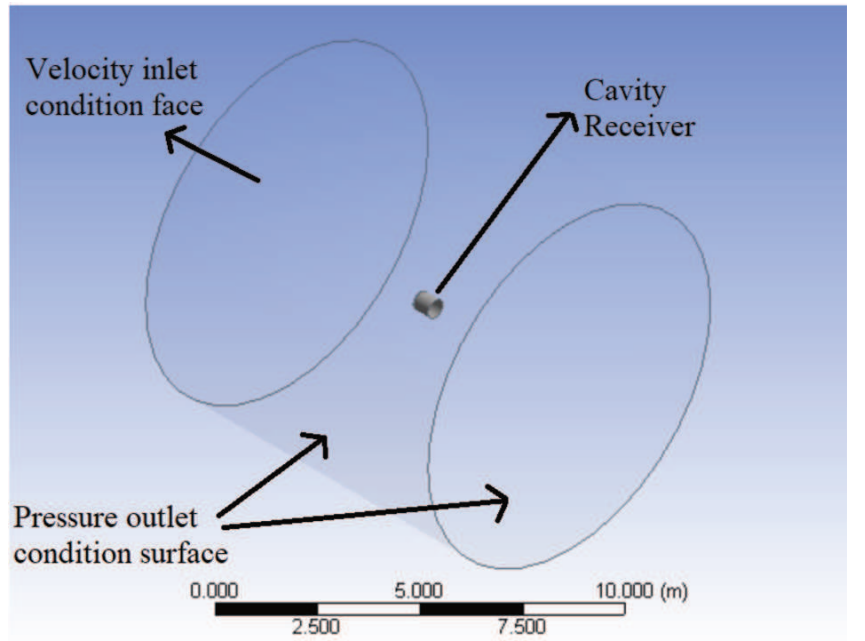

Figure 1: Cylindrical enclosure for cylindrical cavity (Note: Volume of enclosure is 1000 times of cavity)

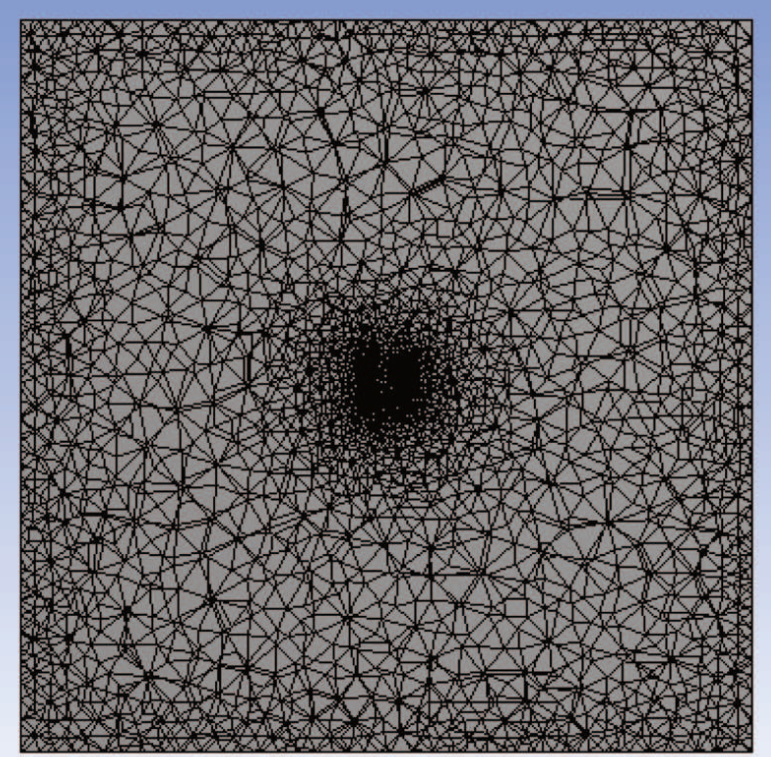

Figure 2: Computational grid 
Table 3:Grid dependency test

\begin{tabular}{l|c|c|c}
\hline $\begin{array}{c}\text { Element } \\
\text { size }(\mathrm{m})\end{array}$ & $\begin{array}{c}\text { Number of } \\
\text { cells }\end{array}$ & $\begin{array}{c}\text { Heat } \\
\text { loss (W) }\end{array}$ & $\begin{array}{c}\text { Percentage change (\%) } \\
\text { w.r.t its predecessor }\end{array}$ \\
\hline 0.5 & 196714 & 4915 & - \\
0.1 & 197238 & 4704 & 4.49 \\
0.05 & 210968 & 5009 & 6.48 \\
0.01 & 815925 & 5066 & 1.14 \\
0.005 & 2593593 & 5101 & 0.7 \\
\hline
\end{tabular}

\subsection{Boundary condition:}

For boundary conditions, the walls of cavities are assigned stainless steel (SS304 grade) material properties with a thickness of $5 \mathrm{~mm}$ and the outer surface is maintained as adiabatic at $300 \mathrm{~K}$. The inner surface is analysed for four isothermal conditions $(600 \mathrm{~K}, 725 \mathrm{~K}, 850 \mathrm{~K}$ and $950 \mathrm{~K})$. Boundary conditions on the surfaces of enclosure are shown in Figure 1. The bottom flat surface of cylindrical enclosure is assigned velocity-inlet condition. The top flat surface and curved surface of enclosure are assigned pressure outlet condition.

\subsection{Computational model:}

The CFD simulation is based on simultaneous solution of the system of equations describing the conservation of mass, momentum, and energy and these can be expressed as follows in equation (1), (2) and (3) respectively [Jiji, 2003]:

$$
\begin{aligned}
& \nabla \vec{V}=0 \\
& \rho \frac{D \vec{V}}{D t}=\rho\left\{\vec{g}-\nabla \vec{p}-\mu \nabla^{2} \vec{V}\right\} \\
& \rho c_{p} \frac{D T}{D t}=\mathrm{k} \nabla^{2} T
\end{aligned}
$$

In the present work, the least Rayleigh number is for $600 \mathrm{~K}$ cavity wall and is $8.8 \times 10^{9}$. Chan and Tien have reported that for laminar flow analysis of cavity receivers, the Rayleigh number must remain below $10^{\circ}$ [Chan and Tien, 1985]. The flow, thus, falls under turbulent flow and compared with other turbulence models, realizable k- $\varepsilon$ turbulence model is more suitable for the flows with complex secondary flow features and the separated flows [Fluent, 2006], thus this model is selected in the present study. The properties of air required for simulations are considered using the correlations provided by Irvine and Liley [Irvine and Liley, 1984]. SIMPLE scheme is used for numerical analysis for its suitability of solving turbulent flow problems and is more stable than other pressurevelocity coupling schemes. Convergence criteria of $10^{-3}$ is maintained for the residuals of continuity and the velocity equations, where as for energy equation it is $10^{-6}$.

\section{Results and discussion}

CFD analysis is conducted on six shapes of cavity receivers at four isothermal temperatures $(600 \mathrm{~K}, 725 \mathrm{~K}, 850 \mathrm{~K}$ and $950 \mathrm{~K})$, each at ten different inclinations $\left(\theta=-90^{\circ}\right.$ to $0^{\circ}$ with $10^{\circ}$ interval)

\subsection{Numerical results:}

The heat loss variation with wall temperature at fixed inclinations is shown in Table 4 for all the shapes. The heat loss is observed to vary linearly with wall temperature. From the literature, the equation governing the convective heat loss [Holman, 1986] is given as:

$$
Q=h \cdot A \cdot \Delta T
$$

Using equation 4 , the linear variation of the heat loss with respect to wall temperature (and aperture area being constant), implies that the heat transfer coefficient must remain constant at a fixed inclination and the same could be observed from Figure 3.

Figure 3(a) shows the heat loss curves at different inclinations from a cylindrical cavity at various isothermal wall temperatures. The curve for $950 \mathrm{~K}$ wall temperature occupies top most values while the $600 \mathrm{~K}$ curves occupies the bottom amongst the 4 wall temperature curves. However, these curves almost merge together when heat transfer coefficient variation is plotted against inclination, as shown in Figure 3(b). This confirms that the heat transfer coefficient is independent of wall temperature at a given inclination and remains constant.
Table 4:Linear variation of Convective heat loss cavity with surface temperature

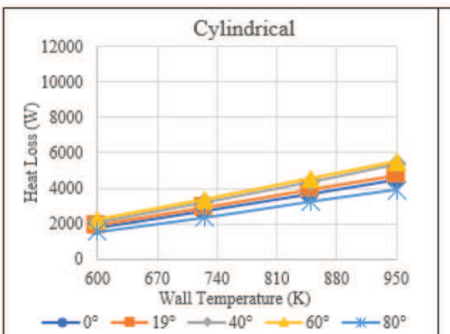

(a)
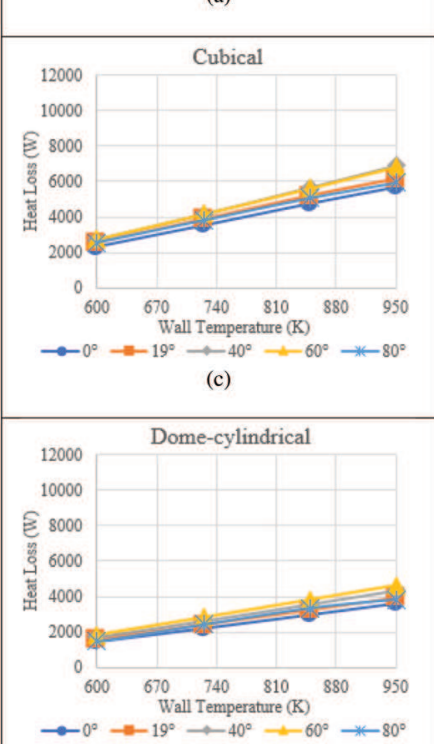

(e)

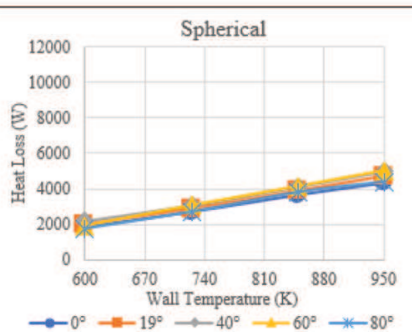

(b)

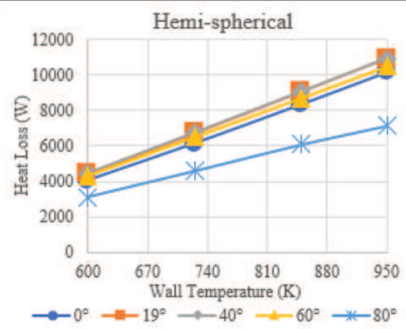

(d)

(f)

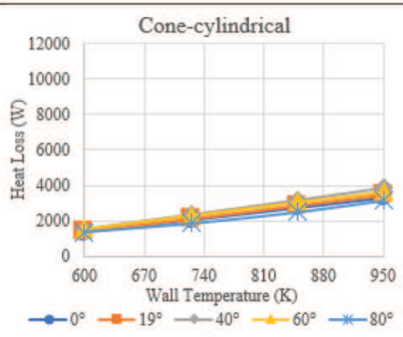

It can be explained as follows: The Nusselt number, $\mathrm{Nu}$, for natural convection is a function of (Grashoff number) ${ }^{0.25}$ and Grashoff number, $\mathrm{Gr}$, is inversely proportional to the square of kinematic viscosity, v [Holman, 1986]. The heat transfer coefficient, h, is directly proportional to the Nusselt number and thermal conductivity, $\mathrm{k}$ [Holman, 1986]. Therefore, heat transfer coefficient is proportional to the ratio of thermal

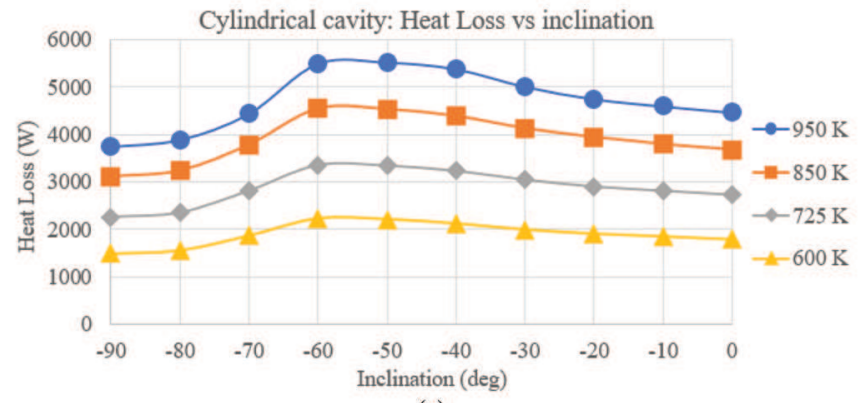

(a)

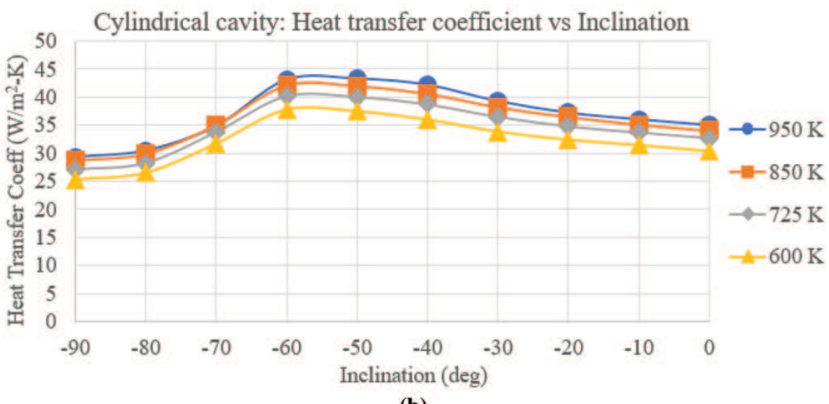

(b)

Figure 3:Variation of heat loss and heat transfer coefficient with inclination for cylindrical cavity 
conductivity to the square root of kinematic viscosity. For the considered operating temperature range $(300 \mathrm{~K}$ to $950 \mathrm{~K})$, it is observed that this ratio remains almost constant (variation $<5 \%$ ) for air and hence the heat transfer coefficient can be assumed to be constant. This makes the heat loss a linear function of temperature difference and almost independent of heat transfer coefficient. Liebfried and Ortjohann have also observed similar trend during their experimental analysis [Liebfried and Ortjohann, 1995].

Figure 4 shows the variation of heat transfer coefficient against inclination for all the six shapes studied in the present analysis. Irrespective of the shape, the trend of the heat transfer coefficient (and consequently the convective heat loss) is observed to first increase, reach a maximum and then decrease as the angle is varied from $\theta=0^{\circ}$ to $\theta=-90^{\circ}$.

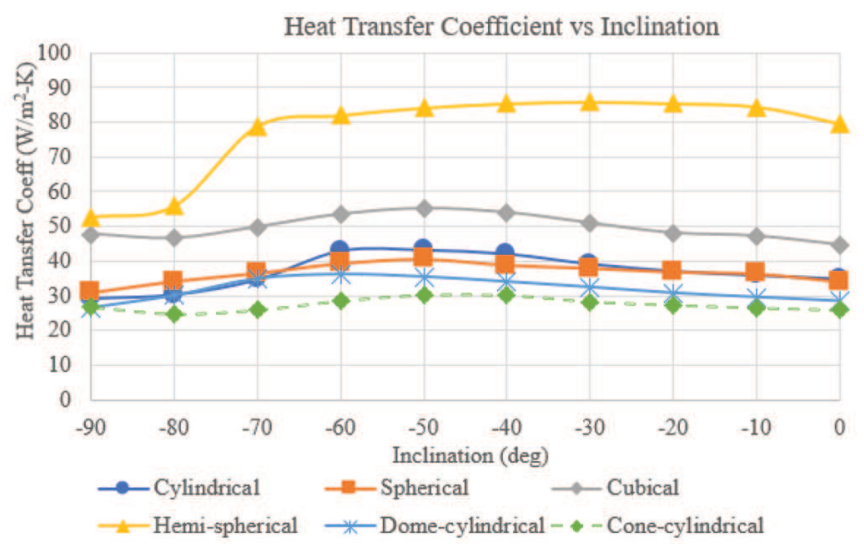

Figure 4: Variation of heat transfer coefficient with inclination for different shapes

The increase of heat transfer coefficient can be understood from velocity contour of cylindrical cavity, shown in Table 5 . The velocity in the lower half of the cavity can be observed to increase as the inclination change from $\theta=0^{0}$ to $\theta=-60^{\circ}$. This increase of velocity in lower half of cavity corresponds to higher turbulence covering more surface area which consequently results in increased activity area and henceforth, increased heat loss.

Table 5: Velocity and velocity vector contours for cylindrical cavity at $950 \mathrm{~K}$ wall temperature

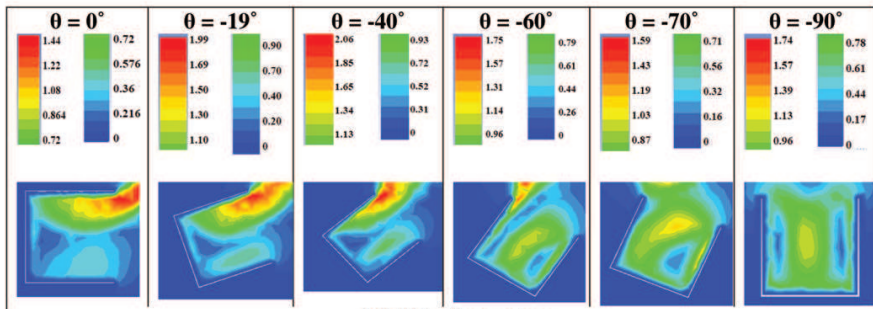

(a) Velocity contour
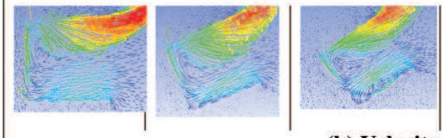

(b) Velocity vector contour

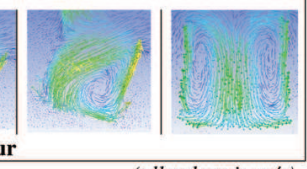

(all values in $\mathrm{m} / \mathrm{s}$ )

The velocity vector contour obtained experimentally by Liebfried and Ortjohann [Liebfried and Ortjohann, 1995] and numerically obtained velocity vectors from present CFD analysis are shown in Figure 5 for hemispherical cavity. Both the contours show similar pattern and it can be observed that as the inclination varies from $\theta=-60^{\circ}$ to $-90^{\circ}$, the circulation of cold air faces resistance from the hot air due to the counterflow rising from all hot walls to the aperture. This decreases the circulation of cold air inside the cavity leading to reduced heat loss. A similar phenomenon can be observed for cylindrical cavity and conecylindrical cavity from their velocity vectors in Table 5 and Table 6 respectively.

The highest heat transfer coefficient, as seen in Figure 4, is experienced by hemispherical cavity. It incurs up to $2.33,1.79,2.33,2.86$ and 3.23 times more heat loss compared to cylindrical, cubical, spherical, domecylindrical and cone-cylindrical cavity shapes respectively. This high
Figure 5: Table 6: Flow pattern obtained for hemispherical cavity through experimental and CFD simulation

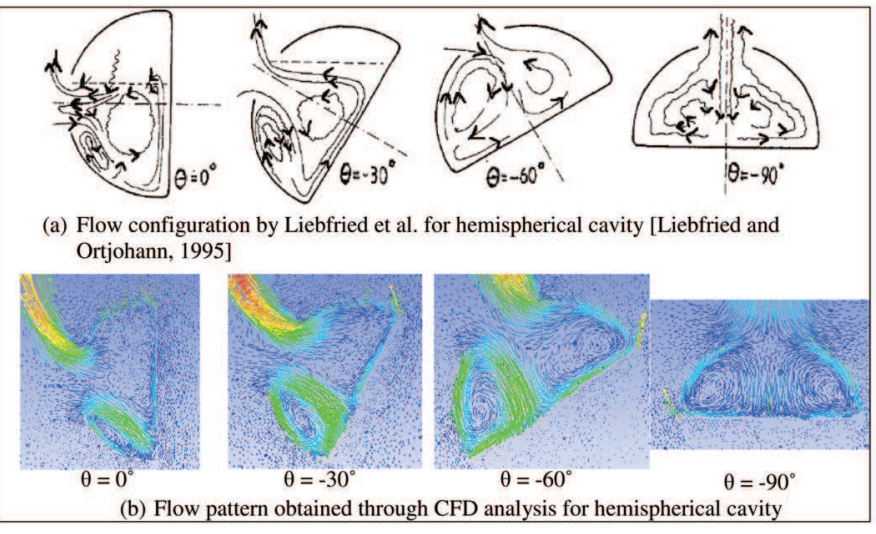

Table 6: Velocity and velocity vector contours for cone-cylindrical cavity at $950 \mathrm{~K}$ wall temperature

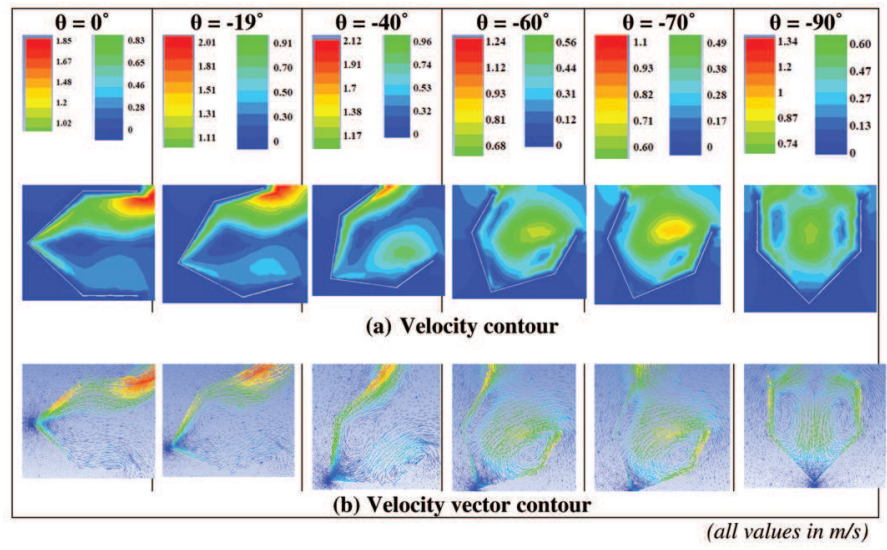

heat loss from hemispherical cavity could be attributed to the fact that it has largest surface area for heat interaction (4 times that of smallest surface area shape, i.e., cone-cylindrical), consequently resulting into large heat transfer.

The cylindrical and spherical shape cavities show almost the identical amount of heat loss all throughout the range of temperatures and inclination. The cubical cavity is observed to exceed cylindrical cavity by 1.23 times to 1.66 times in terms of heat loss across different inclinations and wall temperature conditions. This could also be attributed to its larger surface area availability (1.27 times the cylindrical cavity).

The flow pattern of air stream is the most unique for cone-cylindrical cavity as shown in velocity vector contours in Table 6 . The air stream is observed to not completely penetrate the bottom region of the conical section which reduces the heat interaction area significantly. Therefore, this advantage makes the cone-cylindrical cavity shapes the optimum shape for solar flux heat utilization amongst all the six shapes analyzed so far.

For convenience of readers, the velocity contours for all the cavity receivers at various inclinations are presented in Table 7 for an isothermal wall temperature of $950 \mathrm{~K}$.

\subsection{Data validation}

For data validation, experimental results obtained by Liebfried and Ortjohannfor upward facing spherical cavityis used [Liebfried and Ortjohann, 1995]. CFD analysis is conducted to simulate this upward facing spherical cavity (for twelve data points: four different inclinations between $\theta=0^{0}$ to $-90^{\circ}$ at three isothermal wall temperature conditions each: $573 \mathrm{~K}, 723 \mathrm{~K}$ and $873 \mathrm{~K}$ ) using the methodology employed in previous section and the results are plotted as shown in Figure 6. It is observed that amongst the twelve cases of CFD analysis, eleven cases report less than $11 \%$ deviation and one case is observed to have $18 \%$ deviation from experimental data. These numerical results firmly validate the methodology used for numerical analysis.

\section{Conclusion}

Numerical analysis of upward facing cavity receiver for six different shapes with equal aperture and depth was conducted for examining the convective heat losses. It can be concluded that for a fixed inclination, 
Table 7:Velocity contour at different inclination and $950 \mathrm{~K}$ wall temperature
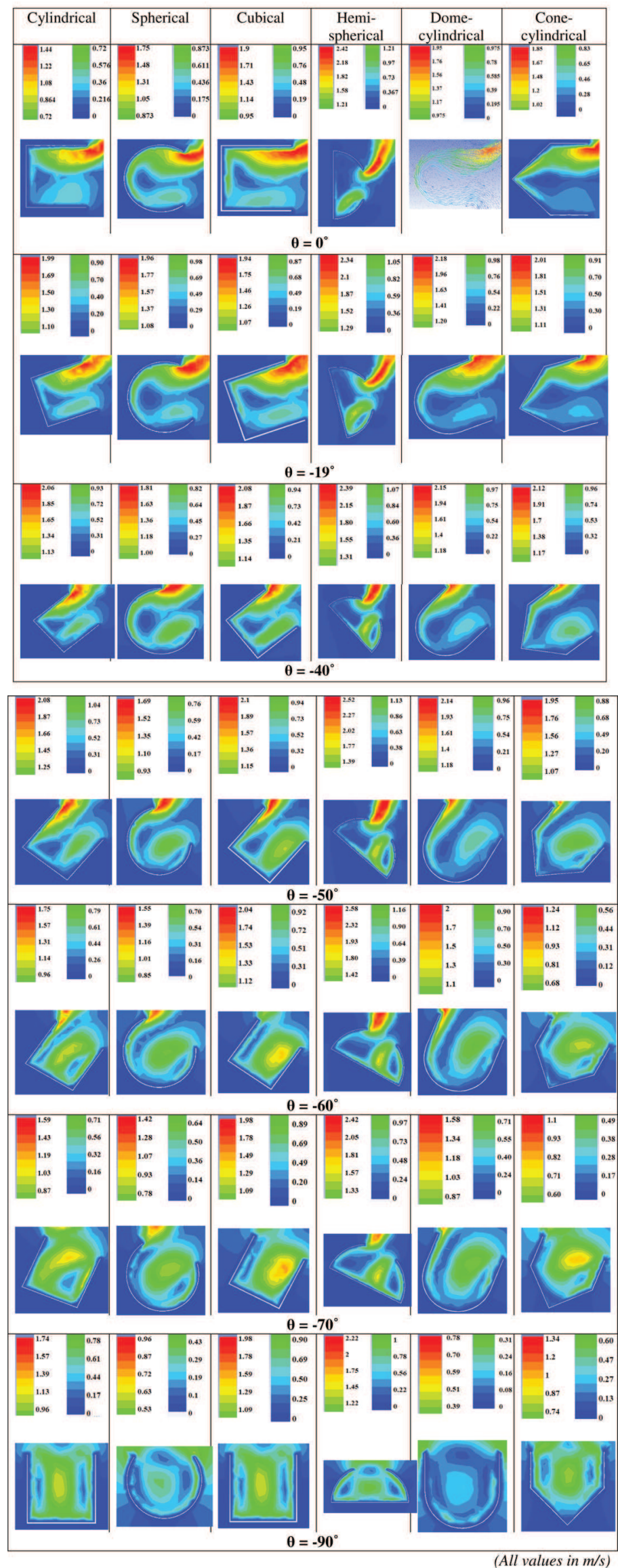

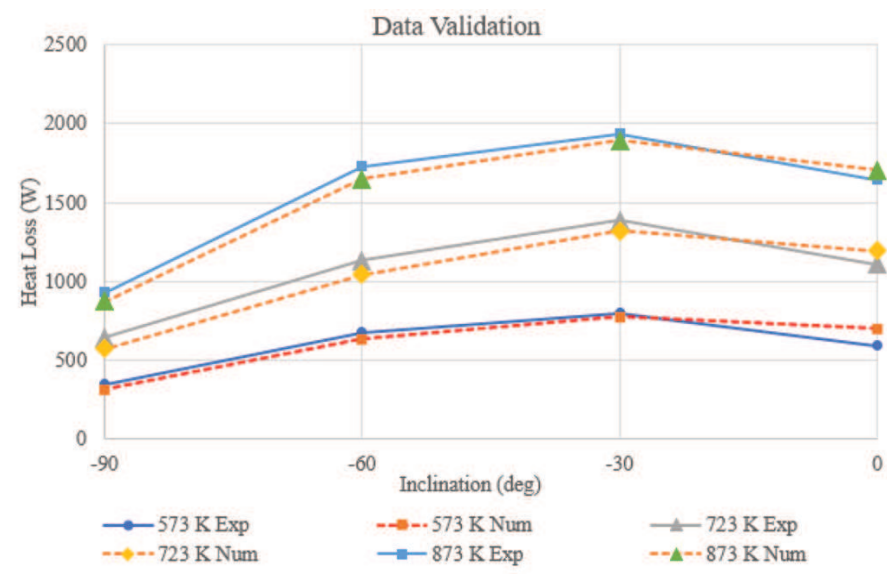

Figure 6: Data Validation of simulation result with experimental results

heat loss varies linearly with surface temperature, implying that the heat transfer coefficient is almost constant. Moreover, with wall temperature fixed, the heat loss for all the shapes was observed to increase up to certain inclination, reach a maximum and then decrease. Among the six shapes analysed, the cone-cylindrical cavity is the most efficient in terms of solar flux utilization whereas hemispherical cavity results in maximum heat loss (3.23 times heat loss compared to cone-cylindrical cavity). Hemispherical cavity compared to the cylindrical, cubical, spherical and dome-cylindrical cavity shapes results up to $2.33,1.79,2.33$ and 2.86 times more heat loss respectively.

\section{Acknowledgement}

The authors acknowledge the financial support from ONGC Energy Centre, Delhi, India, to carry out the present work.

\section{References:}

Brahma Kumaris WRT. 1997. Retrieved September 11, 2019 fromhttp://www.cshindia.in/ images/Cooking/Gyansarovar.pdf

Chan, Y.L. and Tien, C.L. 1985. A numerical study of two-dimensional laminar natural convection in shallow open cavities. International journal of Heat Mass Transfer,

28(3), 603-612.

Dow Chemical Company. 1997. DowTherm A Heat Transfer Fluid. Retrieved September 11, 2019 from http://msdssearch.dow.com/PublishedLiteratureDOWCOM/ dh_0030/0901b803800303cd.pdf

Fluent Inc., 2006. FLUENT 6.3 User's Guide, pp. 12-7.

Gadhia Solar Energy Pvt. Ltd. (GSEP). 2008. Retrieved September 11, 2019 from http://www.cshindia.in/images/Cooling/Kailash.pdf

Gunther, M. and Shahbazfar, R. 2011. Solar dish technology. Advanced CSP teaching materials, 1, 1-63

Holman, J. P. 1986. Heat Transfer (6th ed.). Singapore: McGraw-Hill.

Irvine, T.F. and Liley, P.E., 1984. Steam and Gas Tables with Computer Equations. Academic Press, Orlando.

Iwadate, Y., Okada, I. and Kawamura, K. 1982. Density and heat capacity of molten sodium nitrite-potassium nitrate mixtures. Journal of Chemical Engineering, 27(3), 288290

Jiji, L.M., 2006. Heat Convection, Springer-Verlag, Berlin.

Jilte, R.D., Kedare, S.B. and Nayak, J.K. 2014. Investigation on Convective Heat Losses from Solar Cavities.Energy Procedia, 57, 437-446.

Kedare, S.B., Nayak, J.K. and Paranjape, A.D. 2006. Development, installation and evaluation of large scale concentrating solar collector for medium temperature industrial thermal applications. IIT bombay R\&D project (IRCC No. 04MN001) sponsered by Ministry of New and Renewable Energy, Government of India.

Liebfried, U. and Ortjohann, J. 1995. Convective Heat Loss from Upward and DownwardFacing Cavity Solar Receivers: Measurements and Calculations, Solar Energy Engineering, 117(2), 75-84.

Lovegrove, K., Zawadski, A. and Conventy, J. 2006. Taking the Anu big dish to commercialization.Proceedings of the Solar 2006: Clean Energy?-Can Do! (ANZSES '06), Canberra, Australia.

Munir, A., Hensel, O. and Scheffler, W. 2010. Design principle and calculations of a Scheffler fixed focus. Solar Energy, 84, 1490-1502.

Taylormade Solar Solutions Pvt. Ltd. 2012. Concentrated solar thermal heat India. Retrieved September 11, 2019 from http://www.cshindia.in/images/ProcessHeat/ Hindusthan\% 20Vidyut\%20Products.pdf

World Renewable Spiritual Trust (WRST). 2017. Retrieved September 11, 2019 from http://www.india-one.net/ 